\title{
Resuscitation with an Intact Cord Enhances Pulmonary Vasodilation and Ventilation with Reduction in Systemic Oxygen Exposure and Oxygen Load in an Asphyxiated Preterm Ovine Model
}

\author{
Praveen Chandrasekharan ${ }^{1, * \mathbb{D}}$, Sylvia Gugino ${ }^{1}$, Justin Helman ${ }^{1}$, Carmon Koenigsknecht ${ }^{1}$, Lori Nielsen ${ }^{1}$, \\ Nicole Bradley ${ }^{1}$, Jayasree Nair ${ }^{1}{ }^{D}$, Vikash Agrawal ${ }^{2}$, Mausma Bawa ${ }^{1}$, Andreina Mari ${ }^{1} \mathbb{D}$, Munmun Rawat $^{1}$ \\ and Satyan Lakshminrusimha ${ }^{3}$ (D)
}

Citation: Chandrasekharan, $\mathrm{P}$

Gugino, S.; Helman, J.;

Koenigsknecht, C.; Nielsen, L.; Bradley, N.; Nair, J.; Agrawal, V.; Bawa, M.; Torrealba, A.M.; et al. Resuscitation with an Intact Cord Enhances Pulmonary Vasodilation and Ventilation with Reduction in Systemic Oxygen Exposure and Oxygen Load in an Asphyxiated Preterm Ovine Model. Children 2021, 8, 307. https://doi.org/10.3390/ children 8040307

Academic Editor: Simone Pratesi

Received: 1 April 2021

Accepted: 15 April 2021

Published: 17 April 2021

Publisher's Note: MDPI stays neutral with regard to jurisdictional claims in published maps and institutional affiliations.

Copyright: (c) 2021 by the authors. Licensee MDPI, Basel, Switzerland. This article is an open access article distributed under the terms and conditions of the Creative Commons Attribution (CC BY) license (https:// creativecommons.org/licenses/by/ $4.0 /)$
1 Department of Pediatrics, Jacobs School of Medicine \& Biomedical Sciences, University at Buffalo, Buffalo, NY 14260, USA; sfgugino@buffalo.edu (S.G.); jhelman@buffalo.edu (J.H.); carmonko@buffalo.edu (C.K.); lnielsen@buffalo.edu (L.N.); nkbradle@buffalo.edu (N.B.); jnair2@buffalo.edu (J.N.); mausmaba@buffalo.edu (M.B.); amaritor@buffalo.edu (A.M.); mrawat@upa.chob.edu (M.R.)

2 Department of Pediatrics, Loma Linda University, Loma Linda, CA 92350, USA; dragrawalmd@gmail.com

3 Department of Pediatrics, Division of Neonatology, University of California Davis School of Medicine, Sacramento, CA 95817, USA; slakshmi@ucdavis.edu

* Correspondence: pkchandr@buffalo.edu

Abstract: (1) Background: Optimal initial oxygen $\left(\mathrm{O}_{2}\right)$ concentration in preterm neonates is controversial. Our objectives were to compare the effect of delayed cord clamping with ventilation (DCCV) to early cord clamping followed by ventilation (ECCV) on $\mathrm{O}_{2}$ exposure, gas exchange, and hemodynamics in an asphyxiated preterm ovine model. (2) Methods: Asphyxiated preterm lambs (127-128 d) with heart rate $<90 \mathrm{bpm}$ were randomly assigned to DCCV or ECCV. In DCCV, positive pressure ventilation (PPV) was initiated with $30-60 \% \mathrm{O}_{2}$ and titrated based on preductal saturations $\left(\mathrm{SpO}_{2}\right)$ with an intact cord for $5 \mathrm{~min}$, followed by clamping. In ECCV, the cord was clamped, and PPV was initiated. (3) Results: Fifteen asphyxiated preterm lambs were randomized to DCCV $(\mathrm{N}=7)$ or ECCV $(\mathrm{N}=8)$. The inspired $\mathrm{O}_{2}(40 \pm 20 \%$ vs. $60 \pm 20 \%, p<0.05)$ and oxygen load (520 (IQR 414-530) vs. 775 (IQR 623-868), p-0.03) in the DCCV group were significantly lower than ECCV. Arterial oxygenation and carbon dioxide $\left(\mathrm{PaCO}_{2}\right)$ levels were significantly lower and peak pulmonary blood flow was higher with DCCV. (4) Conclusion: In asphyxiated preterm lambs, resuscitation with an intact cord decreased $\mathrm{O}_{2}$ exposure load improved ventilation with an increase in peak pulmonary blood flow in the first $5 \mathrm{~min}$.

Keywords: delayed cord clamping; oxygen exposure; preterm neonates

\section{Introduction}

In the delivery room, a depressed preterm neonate often needs positive pressure ventilation (PPV) with supplemental oxygen [1]. In a surfactant deficient state complicated by birth asphyxia, the current recommendations to start ventilation with $21-30 \%$ oxygen $\left(\mathrm{O}_{2}\right)$ may not achieve target saturations $\left(\mathrm{SpO}_{2}\right)$ [2-4]. Inability to achieve target $\mathrm{SpO}_{2}$ by $5 \mathrm{~min}$ is associated with poor outcomes in preterm infants. Birth asphyxia could increase pulmonary vascular resistance (PVR) and impair pulmonary vascular transition at birth. In a subgroup analysis of the Targeted Oxygen in the Resuscitation of Preterm Infants and their Developmental Outcomes (To2rpido) trial by Oei et al. <28-week gestation preterm infants resuscitated with $21 \% \mathrm{O}_{2}$ had higher mortality due to respiratory failure, compared to $100 \% \mathrm{O}_{2}$ [5]. Previously, we have shown that ventilation with $100 \% \mathrm{O}_{2}$ (but not $21 \%$ ), led to a decrease in PVR and increased systemic to pulmonary pressure gradient in preterm lambs [6]. Such impaired pulmonary vascular transition at birth could explain the higher 
mortality demonstrated by Oei et al. in <28-week infants resuscitated with $21 \%$ oxygen [5]. Although $100 \% \mathrm{O}_{2}$ exposure in preterm lambs was associated with improved pulmonary blood flow and preductal $\mathrm{SpO}_{2}$, it also led to supraphysiological arterial oxygenation $\left(\mathrm{PaO}_{2}\right)$ that could lead to hyperoxic injury [6]. With concerns of hyperoxia, higher oxidative injury, the use of $100 \% \mathrm{O}_{2}$ is not recommended [2,3].

The feasibility of delaying the clamping of the cord and its benefits have been studied extensively [1,7-15]. However, optimal oxygenation during delayed cord claming (DCC) and ventilation is not known. Ventilation with an intact cord has been shown to improve cardiovascular transition in both translational animal models and human newborns [10-13,15-24]. It has been recently reported that the preductal $\mathrm{SpO}_{2}$ in neonates who had an intact cord was higher compared to the recommended $\mathrm{SpO}_{2}$ ranges obtained following early cord clamping (ECC) $[13,16,22]$.

Currently, there are no concrete recommendations to delay the clamping of the cord and provide positive pressure ventilation in a depressed preterm neonate [2,3]. We conducted this pilot study to understand the effect of ventilation and supplemental oxygen with an intact cord using an asphyxiated preterm ovine model to address this knowledge gap. We aimed to study the effect of supplementing oxygen with and without an intact cord in the setting of perinatal acidosis, on preductal $\mathrm{SpO}_{2}$, oxygenation, ventilation, and hemodynamic parameters in the first 5 min of resuscitation.

\section{Materials and Methods}

The study was approved by the Institutional Animal Care and Use Committee, University of Buffalo, Buffalo New York, USA and followed the ARRIVE guidelines. Time-dated ewes (127-128 d, gestation), approximately equivalent in lung maturity to preterm neonate $\approx 28$-week gestation were used in this study. The ewes did not receive antenatal steroids. After an overnight fast, the ewes were anesthetized, a caesarean section was performed, and fetal lambs were partially exteriorized. These fetal lambs were instrumented while in placental circulation as described previously [6]. Instrumentation included placement of the right jugular and carotid lines for access, pressure monitoring, and blood draws. A left carotid artery probe was placed to monitor blood flows. The left pulmonary artery probe and ductal arteriosus probe were placed to monitor blood flows. The lambs were intubated, and the lung fluid was drained by gravity.

Asphyxia was induced by umbilical cord occlusion until the heart rate (HR) reached $<90 \mathrm{bpm}$. Once the target HR was achieved, the fetus was randomized to early cord clamping and ventilation (ECCV) or delayed cord clamping and ventilation (DCCV) for $5 \mathrm{~min}$. Our primary objective was to achieve a composite outcome of $\mathrm{HR} \geq 100 \mathrm{bpm}$ and $\mathrm{SpO}_{2}$ $\geq 80 \%$ by $5 \mathrm{~min}$. For this reason, in DCCV, the cord was clamped only after 5 min unless the fetus had a drop in $\mathrm{HR}<60 \mathrm{bpm}$ and ventilation continued. To simulate a real-life clinical scenario, the initial supplemental oxygen $\left(\mathrm{O}_{2}\right)$ concentration was between $30-60 \%$ in both groups and not changed during the first $2 \mathrm{~min}$ of PPV. After $2 \mathrm{~min}$, the $\mathrm{O}_{2}$ concentration was adjusted based on the neonatal resuscitation program (NRP) recommended target preductal $\mathrm{SpO}_{2}$. The titration of $\mathrm{O}_{2}$ was proportional to the difference between observed $\mathrm{SpO}_{2}$ and target $\mathrm{SpO}_{2}$ and was performed every min. In order to obtain an accurate and continuous recording of preductal $\mathrm{SpO}_{2}$, two preductal probes (on the tongue and the right upper limb) were placed.

Oxygen load (OL) was calculated using the following formula, $\mathrm{OL}=\left(\mathrm{VT} \times \mathrm{FiO}_{2}\right) / \mathrm{kg}$, where VT is tidal volume and $\mathrm{FiO}_{2}$ is a fraction of inspired oxygen. Total OL was calculated using the summation of breaths for $5 \mathrm{~min}$ as defined previously [25].

In a depressed, asphyxiated and surfactant-deficient preterm lamb with $\mathrm{HR}<90 \mathrm{bpm}$, our primary objective was to evaluate if titrating supplemental $\mathrm{O}_{2}$ with (DCCV) and without an intact cord (ECCV) would lead to a higher rate of success in achieving target saturations as recommended by neonatal resuscitation program (NRP). The secondary objectives were to assess gas exchange and systemic and pulmonary hemodynamics along with oxygen load in the first 5 min of resuscitation. 
Parametric data are presented as mean and standard deviation and analyzed by ANOVA. Non-parametric data are presented as median and interquartile range and analyzed by the Kruskal-Wallis test. The significance was set at a probability of less than five percent.

\section{Results}

Fifteen preterm lambs were randomized to DCCV (N-7) and ECCV (N-8). The characteristics are shown in Table 1 and were similar.

Table 1. Characteristics of preterm lambs.

\begin{tabular}{ccc}
\hline Characteristics & ECC $+\mathbf{V ~} \mathbf{~} \mathbf{N}=\mathbf{8})$ & DCC $+\mathbf{V ~}(\mathbf{N}=\mathbf{7})$ \\
\hline Gestational age (days) & $127 \pm 0.52$ & $128 \pm 0.84$ \\
\hline Female (N) & 4 & 3 \\
\hline Birth weight $(\mathrm{kg})$ & $3.3 \pm 0.63$ & $3.3 \pm 0.70$ \\
\hline Born by multiplicity (N) & Twin-6 & Twin-4 \\
\hline Heart rate at asphyxia (bpm) & $88 \pm 8$ & $86 \pm 10$ \\
\hline Mean blood pressure at asphyxia $(\mathrm{mmHg})$ & $36 \pm 8$ & $34 \pm 10$ \\
\hline pH before resuscitation & $7.04 \pm 0.08$ & $7.0 \pm 0.08$ \\
\hline $\mathrm{PaCO}_{2}$ before resuscitation $(\mathrm{mmHg})$ & $90 \pm 25$ & $101 \pm 23$ \\
\hline $\mathrm{PaO}_{2}$ before resuscitation $(\mathrm{mmHg})$ & $14 \pm 6$ & $15 \pm 11$ \\
\hline
\end{tabular}

Data presented as numbers or as average and standard deviation. ECC - early cord clamping, DCC—delayed cord clamping, $\mathrm{V}$-ventilation. $\mathrm{PaCO}_{2}$-arterial carbon dioxide, $\mathrm{PaO}_{2}$-arterial oxygenation.

The asphyxiated preterm model had perinatal acidosis as shown in Table 1, which improved significantly with DCCV $(7.02 \pm 0.08)$ compared to ECCV $(6.96 \pm 0.13)$. The difference in $\mathrm{pH}$ was statistically significant throughout the first $5 \mathrm{~min}$ of PPV $(p=0.02)$. The HR improved in both groups by $5 \mathrm{~min}-\mathrm{DCCV}(180 \pm 20 \mathrm{bpm})$ and ECCV $(188 \pm 30 \mathrm{bpm})$. The mean blood pressures in both groups by 5 min were similar (DCCV $(40 \pm 10 \mathrm{mmHg})$ and ECCV $(44 \pm 15 \mathrm{mmHg}))$.

\subsection{Oxygenation}

A higher percentage of lambs achieved preductal saturation targets in the DCCV group $(75 \%)$ in the first $5 \mathrm{~min}$ compared to ECCV (60\%). However, this result was not statistically significant (p-0.065). Preductal $\mathrm{SpO}_{2}$ was significantly higher in the DCCV group compared to ECCV (p-0.01) (Figure 1).

The required oxygen concentration to achieve these target $\mathrm{SpO}_{2}$ were significantly higher in the ECCV group compared to the DCCV group (Figure 2).

Oxygen load (OL) - as mentioned previously, OL was calculated using the tidal volume (TV) per $\mathrm{kg}$ in the first $5 \mathrm{~min}$. The average TV in ECCV and DCCV were $6.0 \pm 1.5 \mathrm{~mL} / \mathrm{kg}$ and $6.0 \pm 2.3 \mathrm{~mL} / \mathrm{kg}$, respectively. The OL with DCCV (520 (414-530) $\left.\mathrm{mLO}_{2} / \mathrm{kg}\right)$ was significantly lower compared to ECCV $\left(775(630-867) \mathrm{mLO}_{2} / \mathrm{kg}\right)(p=0.03)$ as shown in Figure 3. 


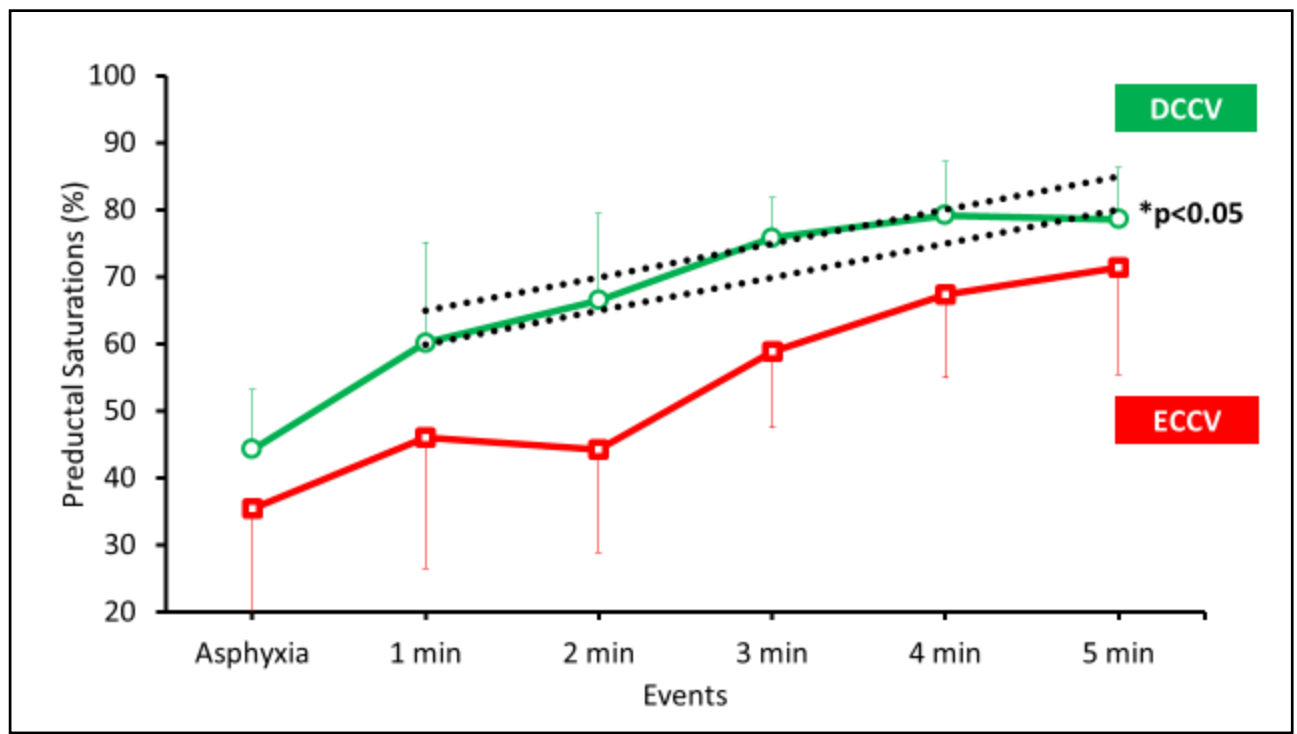

Figure 1. Preductal $\mathrm{SpO}_{2}$ are shown on the y-axis and the events or duration of positive pressure ventilation (PPV) on the x-axis. The data are represented as average and standard deviation. $\mathrm{The}_{\mathrm{SpO}}$ between ECCV (early cord clamping followed by ventilation) and DCCV (delayed cord clamping with ventilation) was significantly different $\left({ }^{*} p<0.05\right.$ by ANOVA).

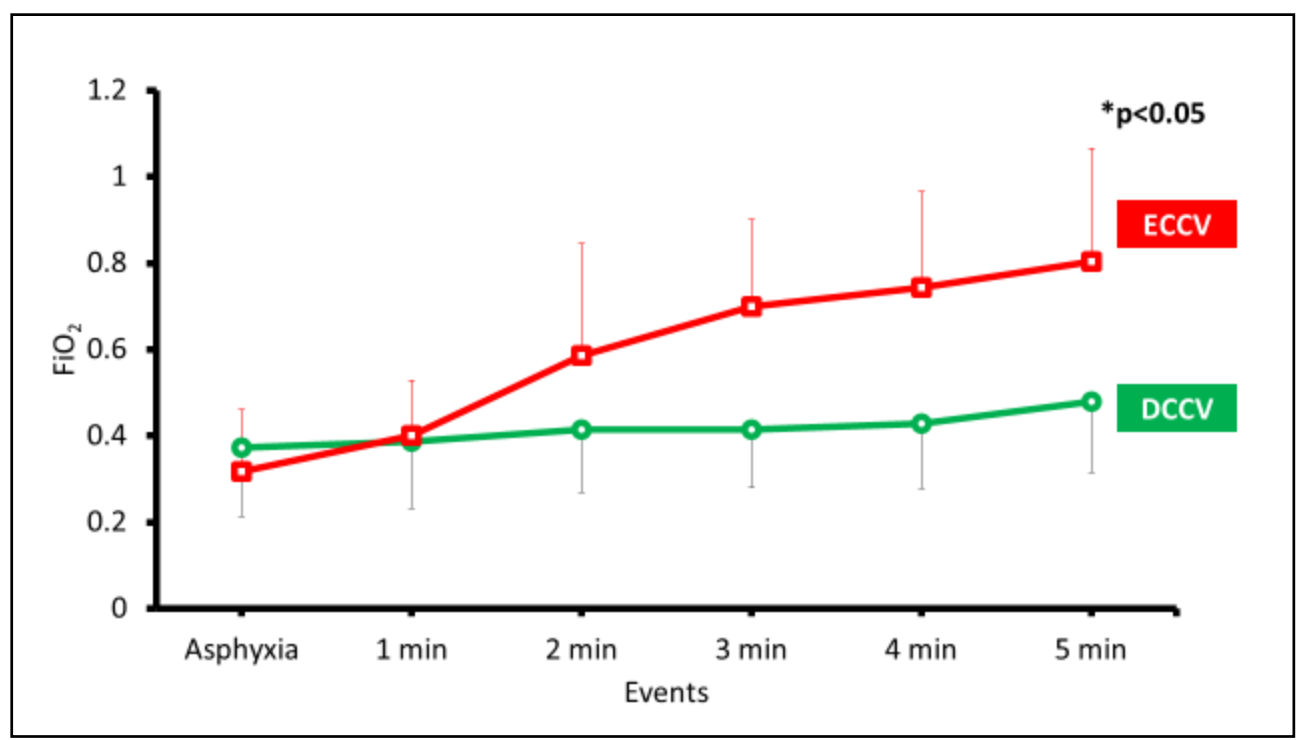

Figure 2. Fraction of inspired oxygen $\left(\mathrm{FiO}_{2}\right)$ is shown on the y-axis and the events or duration of PPV on the $\mathrm{x}$-axis. The data are represented as average and standard deviation. The difference between ECCV and DCCV was significantly different $\left({ }^{*} p<0.05\right.$ by ANOVA).

Arterial oxygenation $\left(\mathrm{PaO}_{2}\right)$-despite the lower percentage of $\mathrm{SpO}_{2}$ targets with $\mathrm{ECCV}$, the $\mathrm{PaO}_{2}$ was significantly higher $(95 \pm 65 \mathrm{mmHg})$ compared to DCCV $(38 \pm 9 \mathrm{mmHg}$, p-0.007) (Figure 4). The variability in arterial oxygenation with DCCV was minimal compared to ECCV, as shown by the standard deviations in Figure 4. The $\mathrm{PaO}_{2} / \mathrm{FiO}_{2}$ ratio at $5 \mathrm{~min}$ of PPV was $98 \pm 50$ in the DCCV group and $135 \pm 87 \mathrm{mmHg}$ in the ECCV group (p-0.4). 


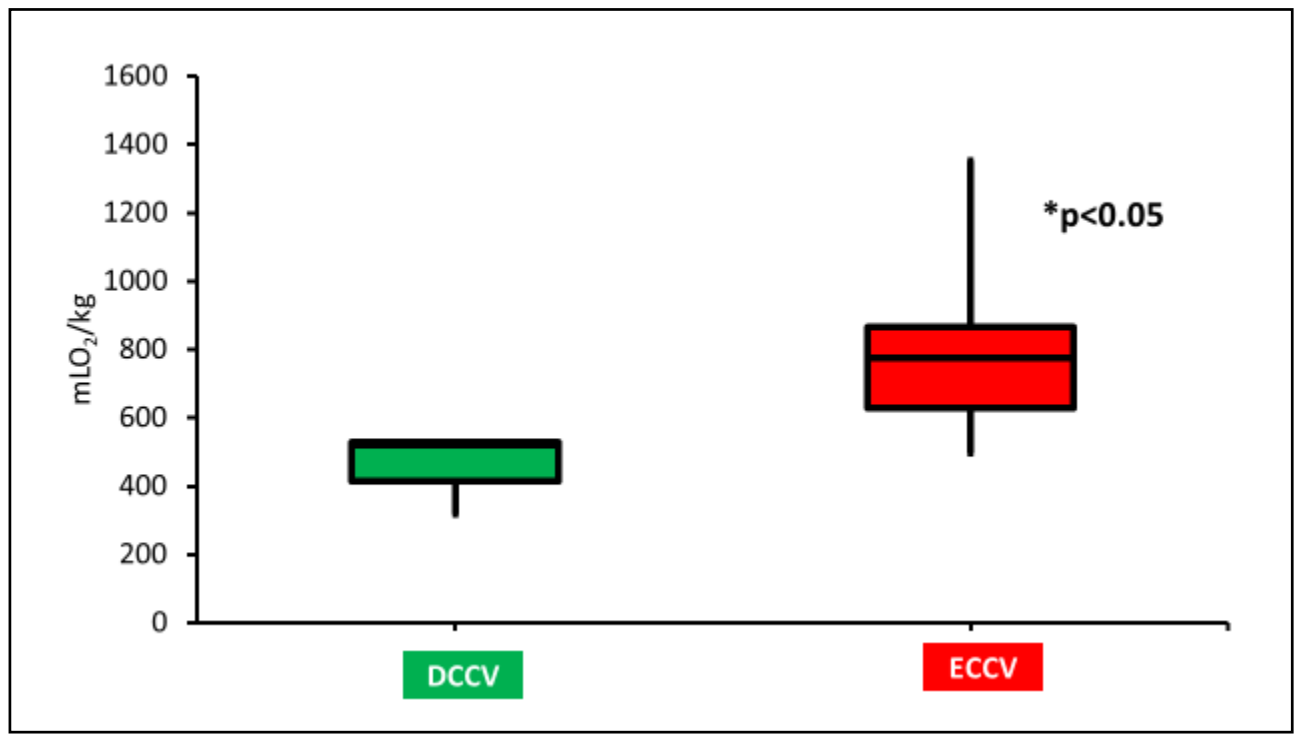

Figure 3. The oxygen load (OL) in milliliters of oxygen per kilogram is shown on the y-axis. The box and whiskers plot shows a significantly higher OL with ECCV compared to DCCV. OL in ECCV was significantly higher compared to DCCV $\left({ }^{*} p<0.05\right.$ by Kruskal-Wallis test).

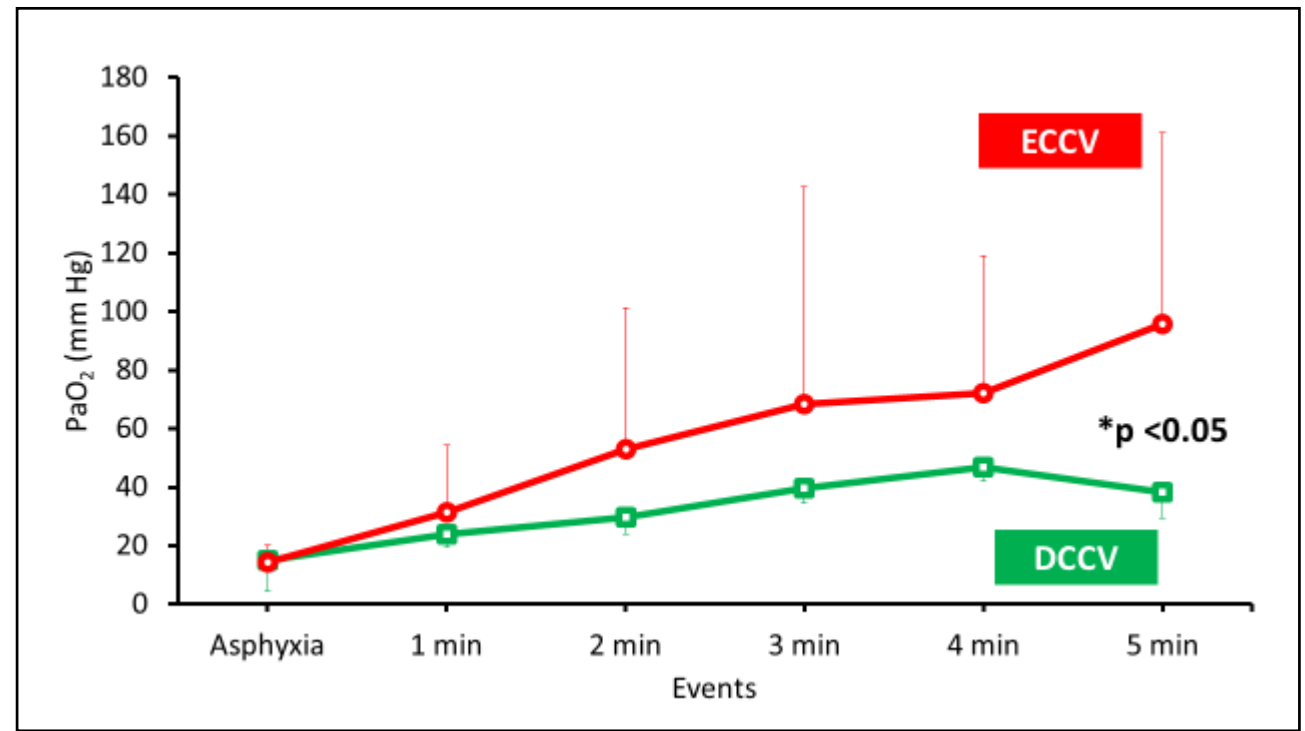

Figure 4. The $\mathrm{PaO}_{2}$ in $\mathrm{mm} \mathrm{Hg}$ is shown on the $\mathrm{y}$-axis and the events or duration of PPV on the x-axis. The $\mathrm{PaO}_{2}$ was significantly lower in DCCV $(* p<0.05$ by ANOVA).

\subsection{Ventilation}

As mentioned previously, despite similar TV and ventilation rates in both groups in the first $5 \mathrm{~min}$, the arterial carbon dioxide $\left(\mathrm{PaCO}_{2}\right)$ levels were significantly lower with DCCV compared to ECCV (Figure 5). 


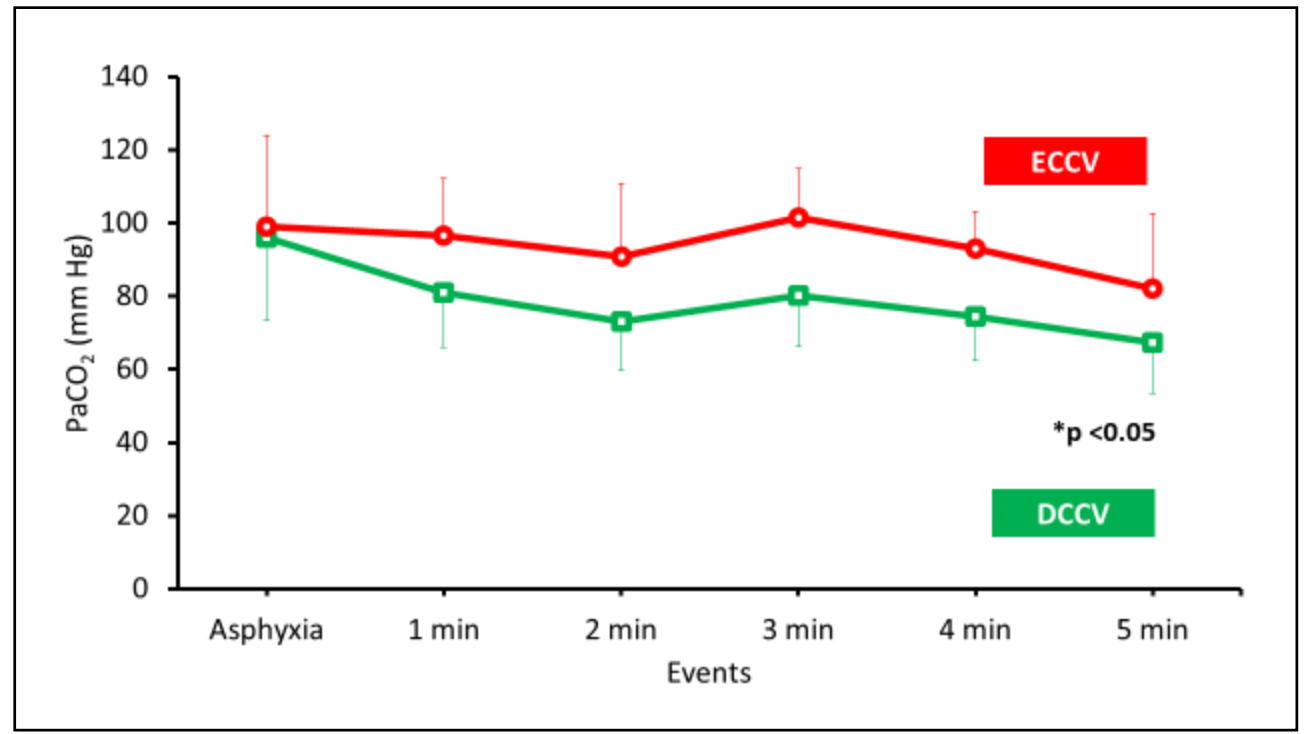

Figure 5. The arterial carbon dioxide $\left(\mathrm{PaCO}_{2}\right.$ in $\left.\mathrm{mmHg}\right)$ is shown on the $\mathrm{y}$-axis and the events on the x-axis. The $\mathrm{PaCO}_{2}$ was significantly lower in DCCV compared to ECCV. ( ${ }^{*} p<0.05$ by ANOVA).

\subsection{Hemodynamics}

Pulmonary blood flow-the peak left pulmonary blood flows (PBF) were significantly higher in the DCCV group compared to ECCV (Figure 6).

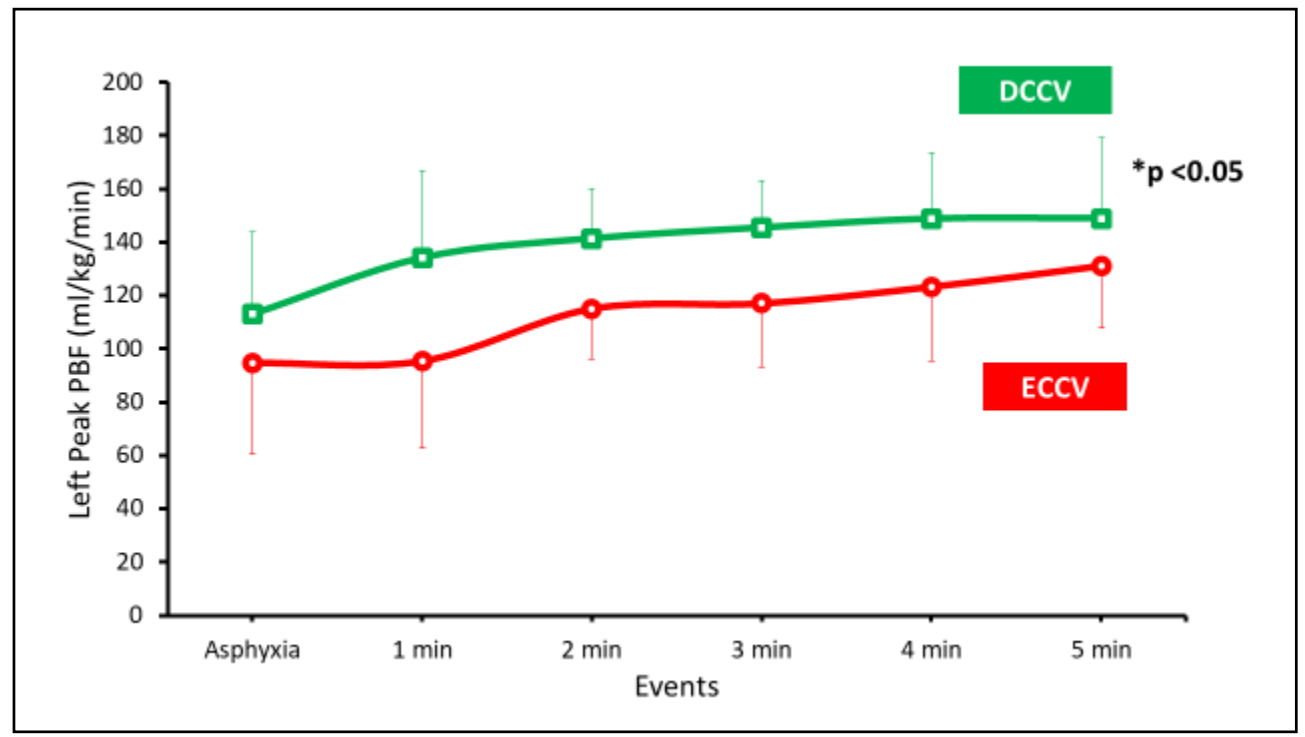

Figure 6. The left peak PBF is shown on the y-axis and the events on the x-axis. The PBF was significantly higher with DCCV compared to ECCV (* $p<0.05$ by ANOVA).

Carotid blood flow-the peak left carotid blood flow (CBF) was not different between the two groups as shown in Figure 7. 


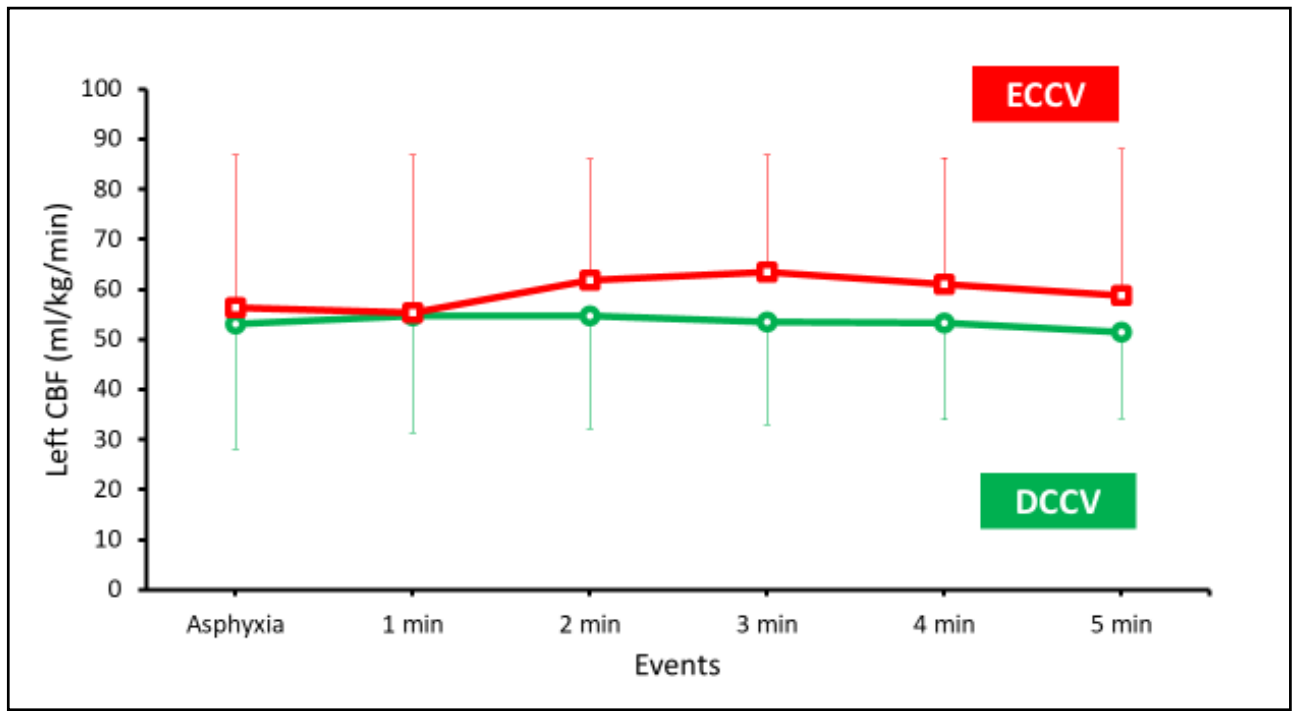

Figure 7. The left peak CBF is shown on the y-axis and the events or duration of PPV on the x-axis.

\section{Discussion}

In a depressed preterm neonate with HRs between 60-90 bpm, lower supplemental $\mathrm{O}_{2}$, as currently recommended by $\mathrm{NRP}$, may not achieve the pre-specified target $\mathrm{SpO}_{2}$ or sustain pulmonary vasodilation. An alternative strategy is to ventilate with an intact cord and higher concentrations of supplemental $\mathrm{O}_{2}$, especially in the setting of perinatal acidosis. Perinatal acidosis increases PVR. Low $\mathrm{FiO}_{2}$ may not increase alveolar oxygen adequately to induce pulmonary vasodilation in preterm infants with high PVR. A combination of increased $\mathrm{FiO}_{2}$ and resuscitation with an intact cord results in "transient alveolar hyperoxia" without systemic hyperoxia due to "buffering" of $\mathrm{PaO}_{2}$ by umbilical venous return (Figures 4 and 8). Such "differential oxygenation" may be an effective concept for the resuscitation of depressed preterm infants that do not show spontaneous respiratory activity. The second advantage of resuscitation with an intact cord is "dual-site" gas exchange enabling $\mathrm{CO}_{2}$ elimination in both the lungs and placenta.

In our pilot study, we tested our concept of "differential oxygenation" and "dualsite gas exchange" in a surfactant-deficient asphyxiated preterm lamb. We assessed the success of achieving target preductal saturation, gas exchange, and hemodynamics during ventilation with an intact cord as compared to the current standard of early cord clamping followed by resuscitation.

Arterial $\mathrm{PaCO}_{2}$ levels were significantly lower in the DCCV group despite similar inflation pressures, tidal volumes, and ventilator rates (Figure 5). We speculate the contribution of placental gas exchange during resuscitation with an intact cord for this decrease. More efficient ventilation leads to earlier normalization of $\mathrm{pH}$ with DCCV. Early normalization of $\mathrm{PaCO}_{2}$ increases pulmonary blood flow and avoids cerebral hyperemia.

The success in achieving the target preductal $\mathrm{SpO}_{2}$ in asphyxiated preterm lambs was similar in DCCV (75\%) compared to ECCV (60\%) lambs, although DCCV lambs required significantly lower $\mathrm{FiO}_{2}$. Previous clinical studies have shown improved $\mathrm{SpO}_{2}$ in the first few minutes after birth with an intact cord compared to immediate cord clamping $[16,18,22]$. Recently, the preductal $\mathrm{SpO}_{2}$ curves in spontaneous breathing term infants with an intact cord for a min were developed by Padilla-Sánchez et al. These curves show increased $\mathrm{SpO}_{2}$ compared to immediate cord clamping, as shown in a study published by Dawson et al. [13]. 


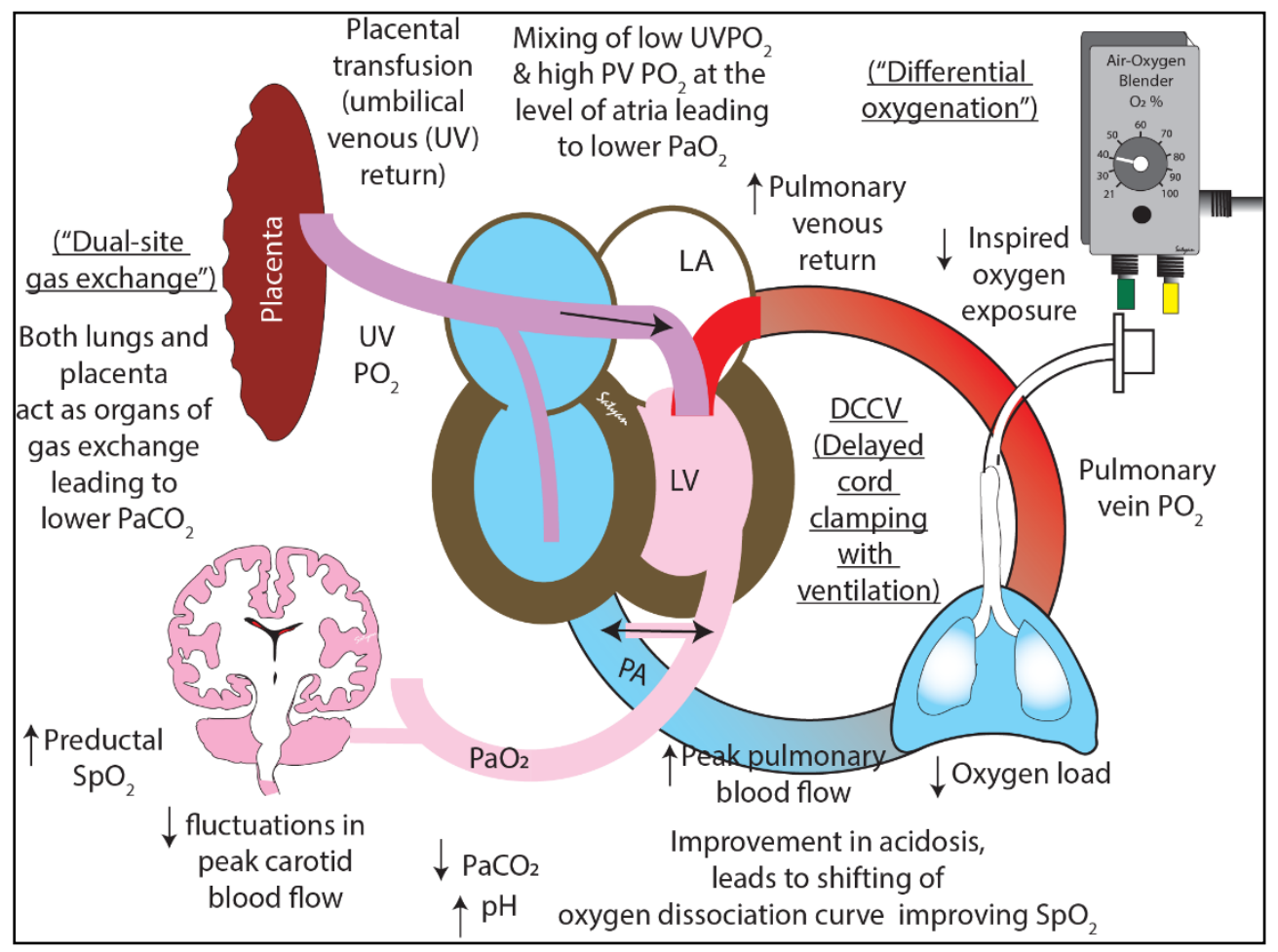

Figure 8. The benefits of delayed cord clamping and ventilation (DCCV) for $5 \mathrm{~min}$ in a lamb model of preterm asphyxia. With positive pressure ventilation and an intact cord, there was a mixing of lower umbilical vein oxygen tension $\left(\mathrm{UVPO}_{2}\right)$ with higher pulmonary venous oxygen tension $\left(\mathrm{PVO}_{2}\right)$ leading to overall systemic lower oxygen tension $\left(\mathrm{PaO}_{2}\right)$ - "differential oxygenation" with alveolar hyperoxia but systemic normoxia. With the placenta and lungs simultaneously acting as organs of gas exchange, the arterial carbon dioxide $\left(\mathrm{PaCO}_{2}\right)$ was lower ("dual-site gas exchange"). Copyright Satyan Lakshminrusimha.

Our study's striking feature was that the arterial oxygenation was much lower with decreased variability (as observed by lower standard deviations) in the DCCV group compared to the ECCV in the first $5 \mathrm{~min}$. We speculate that the mixing of higher $\mathrm{PO}_{2}$ pulmonary venous return with lower $\mathrm{PO}_{2}$ in the umbilical venous return in the atrium, reduces systemic oxygenation as evidenced by lower $\mathrm{PaO}_{2} / \mathrm{FiO}_{2}$ ratios in the DCCV lambs. We speculate that, with a mix of $\mathrm{PO}_{2}$ from the placenta and lungs, these term babies would have had lower $\mathrm{PaO}_{2}$ compared to infants breathing with their umbilical cord cut despite higher $\mathrm{SpO}_{2}$.

Despite lower $\mathrm{PaO}_{2}$ in $\mathrm{DCCV}$, the $\mathrm{SpO}_{2}$ was significantly higher compared to ECCV. We speculate that the better $\mathrm{SpO}_{2}$ reading in the DCCV lambs is due to two factors: better perfusion and prevention of a rightward shift in hemoglobin oxygen dissociation curve due to the rapid correction of acidosis. Asphyxia with combined respiratory and metabolic acidosis shifts the hemoglobin-oxygen dissociation curve leading to lower $\mathrm{SpO}_{2}$ for a given $\mathrm{PaO}_{2}$. We speculate that with better ventilation $\left(\right.$ lower $\left.\mathrm{PaCO}_{2}\right)$ and higher $\mathrm{pH}$ in the DCCV group, $\mathrm{SpO}_{2}$ values were higher despite lower $\mathrm{PaO}_{2}$ levels in DCCV compared to ECCV [26]. By $5 \mathrm{~min}$, the highest $\mathrm{PaO}_{2}$ in $\mathrm{DCCV}$ was $38 \pm 9 \mathrm{mmHg}$ compared to $\mathrm{ECCV}$, where it was $96 \pm 65 \mathrm{mmHg}$. In a study, involving term neonates, Kapadia et al. have shown that perinatal acidemia and post-resuscitation hyperoxemia (defined as an initial $\mathrm{PaO}_{2}$ of $>100 \mathrm{mmHg}$ ) were associated with a higher incidence of hypoxic ischemic encephalopathy [27]. It is prudent to avoid high systemic $\mathrm{PaO}_{2}$ and $\mathrm{PaCO}_{2}$ values in asphyxiated preterm infants to limit cerebral hyperemia and oxidative reperfusion injury. Such injury can also predispose infants to intraventricular hemorrhage (IVH) in preterm neonates $[28,29]$. 
The oxygen exposure in the DCCV group was also much lower compared to the ECCV group. Hyperoxia in the delivery room is associated with an inflammatory response in the brain and the heart [30-34]. In a study involving an ovine model, hyperoxic resuscitation after fetal asphyxia led to the cerebral inflammatory response [34]. Secondary to the immature antioxidant response, oxidative injury in preterm infants can modify DNA methylation patterns, thus affecting gene expressions [35]. Lorente-Pozo et al. studied the effect of OL in preterm infants $<32$ weeks who were resuscitated with supplemental $\mathrm{O}_{2}$ on DNA methylome [25]. The study concluded that OL during resuscitation altered DNA methylome that could potentially alter genes related to cell cycle progression, oxidative stress, and DNA repair [25]. In this study, the median OL during stabilization was $644 \mathrm{mLO}_{2} / \mathrm{kg}$, and $>500 \mathrm{mLO}_{2} / \mathrm{kg}$ could alter the methylation pattern. In our study, the $\mathrm{OL}$ in the first $5 \mathrm{~min}$ of resuscitation was $520 \mathrm{mLO}_{2} / \mathrm{kg}$ and was significantly lower than ECCV, which had an OL of $775 \mathrm{mLO}_{2} / \mathrm{kg}$. In this asphyxiated model, the decreased OL observed in the DCCV group can decrease oxidative injury.

The significant improvement in peak left pulmonary blood flow observed in the DCCV was similar to a previous study by Bhatt et al. in a preterm non-asphyxiated ovine model [19]. The increase in PBF could possibly be secondary to stable hemodynamics, better $\mathrm{pH}$ with lower $\mathrm{PaCO}_{2}$ in the DCCV group. Arterial oxygenation plays a great role in pulmonary vascular transition. Although the change point $\left(\mathrm{PaO}_{2}\right.$ value $)$ for pulmonary vascular transition in an asphyxiated preterm neonate/model remains unknown, we have previously shown that in a non-asphyxiated preterm model, a $\mathrm{PaO}_{2}$ of $31 \pm 0.7 \mathrm{mmHg}$ led to a drop in PVR [36]. In our study, we speculate that despite the lower $\mathrm{PaO}_{2}$ observed in the arterial blood, higher alveolar $\mathrm{PAO}_{2}$ helped overcome hypoxic pulmonary vasoconstriction and an improvement in pulmonary vascular transition in the DCCV group [26]. Custer et al. have shown that alveolar hypoxia could worsen hypoxic pulmonary vasoconstriction leading to a redistribution of pulmonary blood flow in a newborn ovine model [37]. Moreover, acidosis exacerbates hypoxic pulmonary vasoconstriction and better $\mathrm{pH}$ in DCCV could have ameliorated this effect, thus, leading to improved pulmonary vascular transition compared to ECCV.

Our study had some limitations. The data presented here are only for the first $5 \mathrm{~min}$ to compare the parameters while ventilating with and without an intact cord. We did not perform a sample size/power calculation for this pilot study. We did not collect markers of oxidative stress injury and used OL as a surrogate. The study was done in a controlled setting with multiple experienced personnel and may not be the case in real-life scenarios. Species differences do exist, but this asphyxiated preterm model with surfactantdeficient lungs has been widely used to study gas exchange and hemodynamics in the setting of placental transfusion. Since this was a pilot study and the recommended initial supplemental oxygen range by International Liaison Committee on Resuscitation is 30-60\%, we chose random initial oxygen concentration with an average initial $\mathrm{O}_{2}$ concentration within the specified range. The distribution was similar in both ECCV and DCCV groups as shown in Figure 2.

\section{Conclusions}

In this pilot study, in an asphyxiated preterm ovine model with perinatal metabolic acidosis, ventilation with an intact cord for $5 \mathrm{~min}$ (DCCV), decreased oxygen exposure, decreased oxygen load, with improved ventilation, while increasing peak pulmonary blood flow compared to immediate clamping of the cord and ventilation (ECCV). In the future, we intend to study the effect of DCCV with low (30-60\%) and high (60-100\%) oxygen exposure and its effect on oxidative injury and its impact on pulmonary and systemic hemodynamics. Clinical trials evaluating the resuscitation of extremely preterm infants with an intact cord at different concentrations of supplemental oxygen are warranted. 
Author Contributions: Conceptualization, P.C. and S.L.; methodology, all authors.; software, P.C., S.G., J.H., C.K.; validation, P.C., S.G., J.H., N.B., C.K., L.N., J.N., V.A., M.B., A.M., M.R., S.L.; formal analysis, P.C., S.G., J.H., C.K.; writing-original draft preparation, P.C., S.L.; writing-review and editing, P.C., S.G., J.H., N.B., C.K., L.N., J.N., V.A., M.B., A.M., M.R., S.L.; funding acquisition, P.C., S.L. All authors have read and agreed to the published version of the manuscript.

Funding: This research was funded by NICHD, grant number R03HD096510 (PC), RO1 HD072929 (SL) and NHLBI-K12 HL138052 (PC).

Institutional Review Board Statement: The study was approved by the State University of New York at Buffalo, IACUC ID-PED10085N. All studies were conducted as per IACUC/ARRIVE guidelines.

Informed Consent Statement: Not applicable.

Conflicts of Interest: Satyan Lakshminrusimha is a member of the Neonatal Resuscitation Program Steering Committee of the American Academy of Pediatrics (AAP). The opinions expressed in this manuscript are the author's own and do not reflect the official position of the AAP. All other authors declare no conflict of interest. The funders had no role in the design of the study; in the collection, analyses, or interpretation of data, in the writing of the manuscript, or in the decision to publish the results.

\section{References}

1. American Academy of Pediatrics. Textbook of Neonatal Resuscitation (NRP), 7th ed.; American Academy of Pediatrics: Elk Grove Village, IL, USA, 2016; p. 326.

2. Wyckoff, M.H.; Wyllie, J.; Aziz, K.; de Almeida, M.F.; Fabres, J.; Fawke, J.; Guinsburg, R.; Hosono, S.; Isayama, T.; Kapadia, V.S.; et al. Neonatal Life Support: 2020 International Consensus on Cardiopulmonary Resuscitation and Emergency Cardiovascular Care Science With Treatment Recommendations. Circulation 2020, 142, S185-S221. [CrossRef]

3. Wyckoff, M.H.; Wyllie, J.; Aziz, K.; de Almeida, M.F.; Fabres, J.W.; Fawke, J.; Guinsburg, R.; Hosono, S.; Isayama, T.; Kapadia, V.S.; et al. Neonatal Life Support 2020 International Consensus on Cardiopulmonary Resuscitation and Emergency Cardiovascular Care Science With Treatment Recommendations. Resuscitation 2020, 156, A156-A187. [CrossRef]

4. Welsford, M.; Nishiyama, C.; Shortt, C.; Weiner, G.; Roehr, C.C.; Isayama, T.; Dawson, J.A.; Wyckoff, M.H.; Rabi, Y. International Liaison Committee on Resuscitation Neonatal Life Support Task, F. Initial Oxygen Use for Preterm Newborn Resuscitation: A Systematic Review With Meta-analysis. Pediatrics 2019, 143. [CrossRef]

5. Oei, J.L.; Saugstad, O.D.; Lui, K.; Wright, I.M.; Smyth, J.P.; Craven, P.; Wang, Y.A.; McMullan, R.; Coates, E.; Ward, M.; et al. Targeted Oxygen in the Resuscitation of Preterm Infants, a Randomized Clinical Trial. Pediatrics 2017, 139, e20161452. [CrossRef]

6. Chandrasekharan, P.; Rawat, M.; Gugino, S.F.; Koenigsknecht, C.; Helman, J.; Nair, J.; Vali, P.; Lakshminrusimha, S. Effect of various inspired oxygen concentrations on pulmonary and systemic hemodynamics and oxygenation during resuscitation in a transitioning preterm model. Pediatr. Res. 2018, 84, 743-750. [CrossRef]

7. March of Dimes. Available online: https://www.marchofdimes.org/complications/premature-babies.aspx (accessed on 1 November 2020).

8. Chiruvolu, A.; George, R.; Stanzo, K.C.; Kindla, C.M.; Desai, S. Effects of Placental Transfusion on Late Preterm Infants Admitted to a Mother Baby Unit. Am. J. Perinatol. 2021. [CrossRef]

9. Fogarty, M.; Osborn, D.A.; Askie, L.; Seidler, A.L.; Hunter, K.; Lui, K.; Simes, J.; Tarnow-Mordi, W. Delayed vs early umbilical cord clamping for preterm infants: A systematic review and meta-analysis. Am. J. Obstet. Gynecol. 2018, 218, 1-18. [CrossRef]

10. Katheria, A.; Poeltler, D.; Durham, J.; Steen, J.; Rich, W.; Arnell, K.; Maldonado, M.; Cousins, L.; Finer, N. Neonatal Resuscitation with an Intact Cord: A Randomized Clinical Trial. J. Pediatr. 2016, 178, 75-80.e73. [CrossRef]

11. Knol, R.; Brouwer, E.; van den Akker, T.; DeKoninck, P.; van Geloven, N.; Polglase, G.R.; Lopriore, E.; Herkert, E.; Reiss, I.K.M.; Hooper, S.B.; et al. Physiological-based cord clamping in very preterm infant-Randomised controlled trial on effectiveness of stabilisation. Resuscitation 2020, 147, 26-33. [CrossRef]

12. Mercer, J.S.; McGrath, M.M.; Hensman, A.; Silver, H.; Oh, W. Immediate and delayed cord clamping in infants born between 24 and 32 weeks: A pilot randomized controlled trial. J. Perinatol. 2003, 23, 466-472. [CrossRef]

13. Padilla-Sanchez, C.; Baixauli-Alacreu, S.; Canada-Martinez, A.J.; Solaz-Garcia, A.; Alemany-Anchel, M.J.; Vento, M. Delayed vs Immediate Cord Clamping Changes Oxygen Saturation and Heart Rate Patterns in the First Minutes after Birth. J. Pediatr. 2020, 227, 149-156.e141. [CrossRef]

14. Perlman, J.M.; Wyllie, J.; Kattwinkel, J.; Wyckoff, M.H.; Aziz, K.; Guinsburg, R.; Kim, H.S.; Liley, H.G.; Mildenhall, L.; Simon, W.M.; et al. Part 7: Neonatal Resuscitation: 2015 International Consensus on Cardiopulmonary Resuscitation and Emergency Cardiovascular Care Science With Treatment Recommendations. Circulation 2015, 132, S204-S241. [CrossRef]

15. Pratesi, S.; Montano, S.; Ghirardello, S.; Mosca, F.; Boni, L.; Tofani, L.; Dani, C. Placental Circulation Intact Trial (PCI-T)Resuscitation with the Placental Circulation Intact vs. Cord Milking for Very Preterm Infants: A Feasibility Study. Front. Pediatr. 2018, 6, 364. [CrossRef] 
16. Andersson, O.; Rana, N.; Ewald, U.; Malqvist, M.; Stripple, G.; Basnet, O.; Subedi, K.; Kc, A. Intact cord resuscitation versus early cord clamping in the treatment of depressed newborn infants during the first 10 minutes of birth (Nepcord III)—A randomized clinical trial. Matern Health Neonatol. Perinatol. 2019, 5, 15. [CrossRef]

17. Armanian, A.M.; Badiee, Z. Resuscitation of preterm newborns with low concentration oxygen versus high concentration oxygen. J. Res. Pharm. Pract. 2012, 1, 25-29. [CrossRef]

18. Bancalari, A.; Araneda, H.; Echeverria, P.; Marinovic, A.; Manriquez, C. Arterial oxygen saturation and heart rate in term newborn in the first hour after birth. Rev. Chil. Pediatr. 2019, 90, 384-391. [CrossRef]

19. Bhatt, S.; Alison, B.J.; Wallace, E.M.; Crossley, K.J.; Gill, A.W.; Kluckow, M.; te Pas, A.B.; Morley, C.J.; Polglase, G.R.; Hooper, S.B. Delaying cord clamping until ventilation onset improves cardiovascular function at birth in preterm lambs. J. Physiol. 2013, 591, 2113-2126. [CrossRef]

20. Brouwer, E.; Knol, R.; Vernooij, A.S.N.; van den Akker, T.; Vlasman, P.E.; Klumper, F.; DeKoninck, P.; Polglase, G.R.; Hooper, S.B.; Te Pas, A.B. Physiological-based cord clamping in preterm infants using a new purpose-built resuscitation table: A feasibility study. Arch. Dis. Child Fetal. Neonatal. Ed. 2019, 104, F396-F402. [CrossRef]

21. Hutchon, D.J. Ventilation before Umbilical Cord Clamping Improves Physiological Transition at Birth or "Umbilical Cord Clamping before Ventilation is Established Destabilizes Physiological Transition at Birth". Front. Pediatr. 2015, 3, 29. [CrossRef]

22. Kc, A.; Singhal, N.; Gautam, J.; Rana, N.; Andersson, O. Effect of early versus delayed cord clamping in neonate on heart rate, breathing and oxygen saturation during first 10 minutes of birth-randomized clinical trial. Matern Health Neonatol. Perinatol. 2019, 5, 7. [CrossRef]

23. Polglase, G.R.; Blank, D.A.; Barton, S.K.; Miller, S.L.; Stojanovska, V.; Kluckow, M.; Gill, A.W.; LaRosa, D.; Te Pas, A.B.; Hooper, S.B. Physiologically based cord clamping stabilises cardiac output and reduces cerebrovascular injury in asphyxiated near-term lambs. Arch. Dis. Child Fetal. Neonatal. Ed. 2018, 103, F530-F538. [CrossRef]

24. Polglase, G.R.; Dawson, J.A.; Kluckow, M.; Gill, A.W.; Davis, P.G.; Te Pas, A.B.; Crossley, K.J.; McDougall, A.; Wallace, E.M.; Hooper, S.B. Ventilation onset prior to umbilical cord clamping (physiological-based cord clamping) improves systemic and cerebral oxygenation in preterm lambs. PLOS ONE 2015, 10, e0117504. [CrossRef]

25. Lorente-Pozo, S.; Parra-Llorca, A.; Nunez-Ramiro, A.; Cernada, M.; Hervas, D.; Boronat, N.; Sandoval, J.; Vento, M. The Oxygen Load Supplied during Delivery Room Stabilization of Preterm Infants Modifies the DNA Methylation Profile. J. Pediatr. 2018. [CrossRef]

26. Chandrasekharan, P.; Rawat, M.; Lakshminrusimha, S. How Do We Monitor Oxygenation during the Management of PPHN? Alveolar, Arterial, Mixed Venous Oxygen Tension or Peripheral Saturation? Children 2020, 7, 180. [CrossRef]

27. Kapadia, V.S.; Chalak, L.F.; DuPont, T.L.; Rollins, N.K.; Brion, L.P.; Wyckoff, M.H. Perinatal asphyxia with hyperoxemia within the first hour of life is associated with moderate to severe hypoxic-ischemic encephalopathy. J. Pediatr. 2013, 163, 949-954. [CrossRef]

28. Noori, S.; McCoy, M.; Anderson, M.P.; Ramji, F.; Seri, I. Changes in cardiac function and cerebral blood flow in relation to peri/intraventricular hemorrhage in extremely preterm infants. J. Pediatr. 2014, 164, 264-270.e3. [CrossRef] [PubMed]

29. Noori, S.; Seri, I. Hemodynamic antecedents of peri/intraventricular hemorrhage in very preterm neonates. Semin. Fetal. Neonatal. Med. 2015, 20, 232-237. [CrossRef] [PubMed]

30. Lakshminrusimha, S.; Russell, J.A.; Steinhorn, R.H.; Swartz, D.D.; Ryan, R.M.; Gugino, S.F.; Wynn, K.A.; Kumar, V.H.; Mathew, B.; Kirmani, K.; et al. Pulmonary hemodynamics in neonatal lambs resuscitated with $21 \%, 50 \%$, and $100 \%$ oxygen. Pediatr. Res. 2007, 62, 313-318. [CrossRef] [PubMed]

31. Munkeby, B.H.; Borke, W.B.; Bjornland, K.; Sikkeland, L.I.; Borge, G.I.; Lomo, J.; Rivera, S.; Khrestchatisky, M.; Halvorsen, B.; Saugstad, O.D. Resuscitation of hypoxic piglets with 100\% O2 increases pulmonary metalloproteinases and IL-8. Pediatr. Res. 2005, 58, 542-548. [CrossRef]

32. Wedgwood, S.; Steinhorn, R.H.; Lakshminrusimha, S. Optimal oxygenation and role of free radicals in PPHN. Free Radic. Biol. Med. 2019, 142, 97-106. [CrossRef] [PubMed]

33. Borke, W.B.; Munkeby, B.H.; Halvorsen, B.; Bjornland, K.; Tunheim, S.H.; Borge, G.I.; Thaulow, E.; Saugstad, O.D. Increased myocardial matrix metalloproteinases in hypoxic newborn pigs during resuscitation: Effects of oxygen and carbon dioxide. Eur. $J$. Clin. Investig. 2004, 34, 459-466. [CrossRef] [PubMed]

34. Markus, T.; Hansson, S.; Amer-Wahlin, I.; Hellstrom-Westas, L.; Saugstad, O.D.; Ley, D. Cerebral inflammatory response after fetal asphyxia and hyperoxic resuscitation in newborn sheep. Pediatr. Res. 2007, 62, 71-77. [CrossRef]

35. Hitchler, M.J.; Domann, F.E. An epigenetic perspective on the free radical theory of development. Free Radic. Biol. Med. 2007, 43, 1023-1036. [CrossRef] [PubMed]

36. Chandrasekharan, P.; Lakshminrusimha, S. Oxygen therapy in preterm infants with pulmonary hypertension. Semin. Fetal. Neonatal. Med. 2020, 25, 101070. [CrossRef]

37. Custer, J.R.; Hales, C.A. Influence of alveolar oxygen on pulmonary vasoconstriction in newborn lambs versus sheep. Am. Rev. Respir. Dis. 1985, 132, 326-331. [CrossRef] [PubMed] 